\title{
Effects of Water Depth and Ice Thickness on Ice Cover Blasting for Ice Jam Flood Prevention: A Case Study on the Heilong River, China
}

\author{
Tao Wang ${ }^{1}$, Xinlei Guo ${ }^{1, *(1)}$, Hui Fu ${ }^{1}$, Yongxin Guo ${ }^{1}$, Xuming Peng ${ }^{2}$, Yunan $\mathrm{Wu}^{2}$, \\ Jiazhen $\mathrm{Li}^{1}{ }^{1}$ and Yinyin $\mathrm{Xia}^{1}$ \\ 1 State Key Laboratory of Simulation and Regulation of Water Cycle in River Basin, China Institute of Water \\ Resources and Hydropower Research, Beijing 100038, China; taozy163@163.com (T.W.); \\ hfmax1981@126.com (H.F.); guoyx_1123@163.com (Y.G.); lijiazhen@iwhr.com (J.L.); xiayy@iwhr.com (Y.X.) \\ 2 Support Centre of Flood Control and Drought Relief of Heilongjiang Province, Harbin 150001, China; \\ pxm0451@163.com (X.P.); fxek82627582@163.com (Y.W.) \\ * Correspondence: guoxinlei@163.com or guoxinlei@iwhr.com; Tel.: +86-10-6878-1725
}

Received: 29 April 2018; Accepted: 22 May 2018; Published: 28 May 2018

\begin{abstract}
Ice blasting with explosives is an important method for mitigating or preventing ice jam floods during the spring breakup of frozen rivers. Successful blasting relies on properly determining the relationships between parameters including blasting crater radius, explosive weight, ice cover thickness, and water depth, though variations in the final three factors have significant effects on the blasting crater radius. We conducted field experiments in an upper reach of the Heilong (Amur) River, which forms the border between China and Russia, in order to develop an empirical formula correlating these factors. The blasting crater radius determined by the proposed equation resulted in average errors of less than $8.5 \%$ when compared with the measured values. This formula was used for ice blasting along the upper Heilong River in spring 2016 and 2017, successfully preventing ice jam formation during river breakup and thus providing a scientific basis for the prevention of ice-related flooding in northern regions.
\end{abstract}

Keywords: ice cover blasting; blasting crater radius; ice cover thickness; water depth; explosive weight

\section{Introduction}

The Heilong (or Amur) River is located in northeastern China and serves as the border between China and Russia, where the air temperature typically falls below zero from October to April. The annual average temperature in the region is around $-2{ }^{\circ} \mathrm{C}$, with minimum winter temperatures recorded as low as $-59.5^{\circ} \mathrm{C}$, and the freeze-up period lasts up to six months. The Argun and Shilka Rivers are two large tributaries that combine to form the Heilong River in northern China (Figure 1a). Both rivers flow from southwest to northeast (from lower latitude to higher latitude) over a 700-km distance, causing ice breakup to occur in the upstream reach and tributaries before downstream areas, resulting in reversed breakup conditions that can exacerbate ice jam flooding. The characteristics of the upper Heilong River include a narrow and meandering main channel, connecting islands, a large number of branches and side channels, and steep changes in river gradient, resulting in uneven distribution of the flow and water depth along the river (Figure 1b). These factors lead to frequent ice jam formation during breakup. Since the 1950s, ice jams have occurred almost every year in certain reaches of the Heilongjiang River. Significant ice jam events occur every three years on average in the upper reach of the Heilong River. 


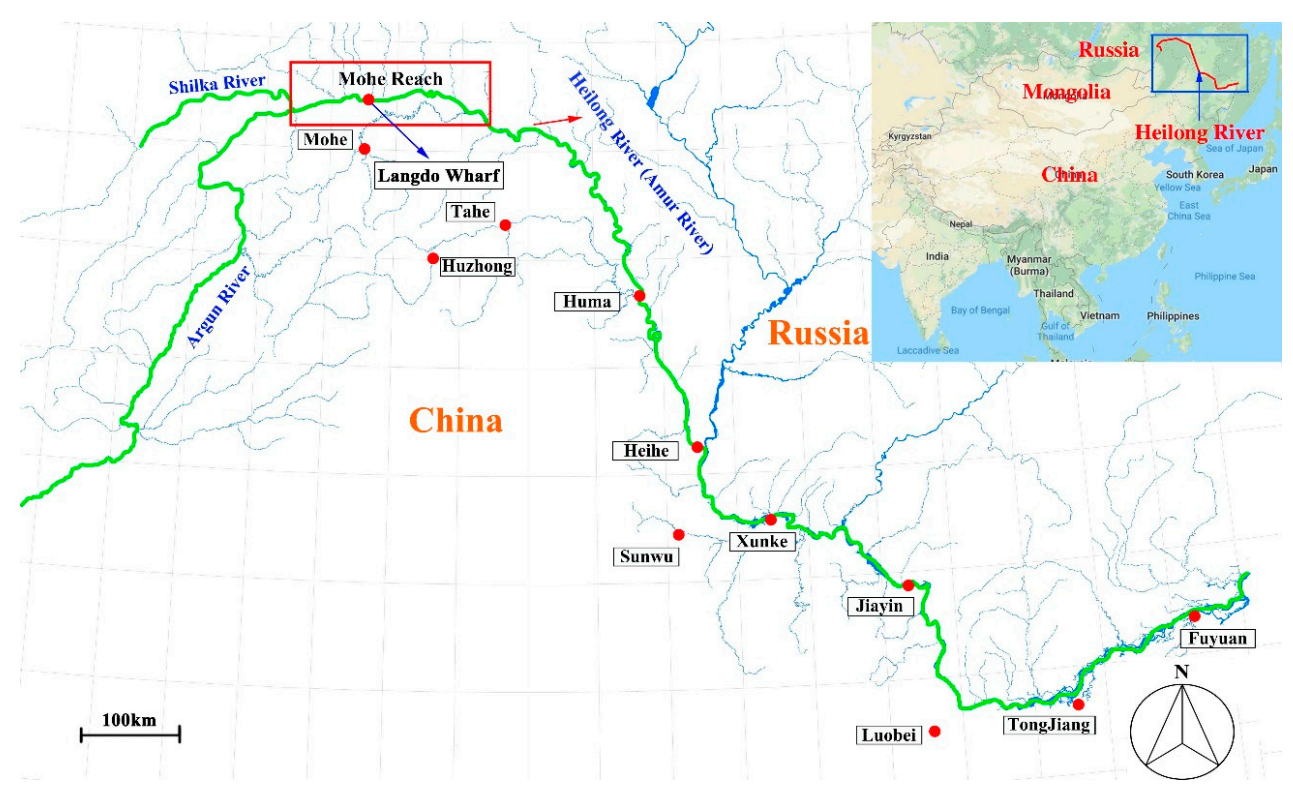

(a)

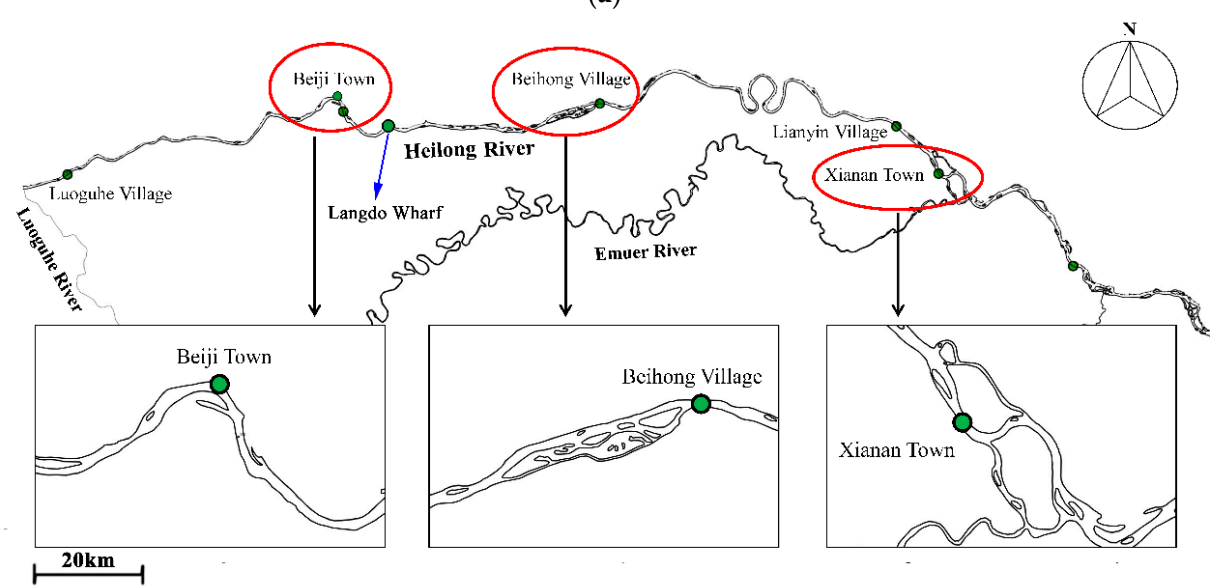

(b)

Figure 1. Study area: (a) Location of the Heilong River and its major tributaries; (b) detail of the Mohe reach on the Heilong River.

Due to its remote location, transportation and communication systems are undeveloped in this region and observational equipment and other relevant technology are lacking or out of date. As a result, research on ice jam flood prevention and mitigation in this region has progressed very slowly. Since the Heilong River serves as an international border, it is impossible to construct hydraulic structures to control and mitigate ice jam flooding. The only available non-structural methods involve preventing the formation of ice jams or removing them [1,2]. Field measurements have shown that ice cover thickness on the Heilong River can reach $2.0 \mathrm{~m}$, making this cover extremely strong. In addition, there is usually about $20 \mathrm{~cm}$ of snow covering the ice. It is difficult to breach and remove a large area of such thick ice cover by mechanical destruction, surface treatment, or thermal modification. Therefore, the blasting of ice by explosives has become the most effective method for ice jam prevention and mitigation on the Heilong River.

Although explosives have been used to break ice cover for about 200 years, systematic research on ice blasting has progressed slowly because the implementation of such research is highly limited by river conditions, the surrounding environment, and the difficulty and risks of field operations $[3,4]$. Based on ice blasting experience, the United States Army Corps of Engineers (USACE) developed empirical prediction curves to express the relationship between blasting radius, ice cover thickness, and 
explosive weight [5,6]. In China, Ding et al. [7] proposed the aerial dropping of bombs into the Yellow River and the launching of bombs from the river bank. Liang et al. [8] analyzed the characteristics of blasting vibration and shock pressure in water based on laying explosives either on or below the ice on the Yellow River in Inner Mongolia. Tong et al. [9] summarized ice cracking and loading distribution after blasting based on field data from the Yellow River and mathematical models. Regarding blasting technologies, Duan et al. [10] and Yin et al. [11] summarized the proper layout for blasting holes and the blasting range of a river channel based on engineering practices. The average ice cover thickness for the studies mentioned above was around $0.5 \mathrm{~m}$ or less, different from the Heilong River, which has thicker and stronger ice cover and shallower water depth.

In order to provide a scientific basis for high-efficiency ice blasting methods in the Heilong River and elsewhere, we performed ice blasting experiments in the Mohe reach of the upper Heilong River and used the information gathered to develop effective ice blasting technologies and establish an empirical formula defining the relationship between the blasting crater radius and the explosive weight, ice cover thickness, and water depth below the ice cover.

\section{Methods}

Ice blasting for ice jam mitigation can be divided into two categories according to the blasting stage. Pre-emptive ice cover blasting is undertaken before breakup to prevent severe ice jam formation; this breaks ice cover into smaller blocks that can flow smoothly downstream during ice breakup before the formation of an ice jam. This method also allows the sun's radiant heat to penetrate into the water and weaken the ice cover in the vicinity of the blasting area through heat transfer. In contrast, ice jam blasting is used to break or destroy existing ice jams, preventing or mitigating their flooding effects. Prevention is considered to be a priority measure for flood damage reduction, so ice cover blasting (before ice jam formation) is an important management technique along the Heilong River that is conducted based on the ice forecast and field measurements [12,13].

\subsection{Selection of Explosive Type, Amount, and Timing}

Research by the USACE showed that there were negligible differences in the blasting effects when using different types of explosives [5]. In China, the Institute of Engineer Corps in China used TNT for ice blasting under water $[14,15]$. TNT and rock emulsion explosives have been used for ice blasting on the Yellow River $[9,16]$. The latter have also been used for ice blasting on the Heilong River [17]. These studies have shown that the type of the explosive used has no apparent effects on the blasting results.

A key factor in ice blasting is the determination of the explosive mass. The USACE [6] published Equation (1) to calculate the optimal explosive mass:

$$
W_{o p t}=21 t^{3}
$$

where $W_{\text {opt }}$ is the optimal amount of explosives $(\mathrm{kg})$ and $t$ is the ice cover thickness $(\mathrm{m})$. This equation was fitted based on a large amount of measured data and shows that the optimal amount of explosives is positively correlated to $t^{3}$. In practice, once the ice cover thickness exceeds $1.0 \mathrm{~m}$, the amount of explosives necessary increases quickly.

For natural rivers with shallow water below the ice cover, the full effect of a large explosive dosage cannot be achieved through the explosive shock wave. When explosives are detonated well below the water's surface, gases with high temperature and pressure are instantly produced, leading to the propagation of spherical shock waves and creating gas bubbles. These bubbles expand against the hydrostatic pressure. After the internal pressure drops below the water pressure, the bubbles continue to expand due to inertia. When the internal pressure drops to $1 / 5$ to $1 / 10$ of the external water pressure, the bubbles start to shrink due to external pressure [18]. Inertia also causes the bubbles to continue shrinking even after the internal pressure exceeds the external water pressure. 
This back-and-forth process continues for some time. Meanwhile, buoyancy causes the bubbles to move toward the water surface, or toward solid boundaries and away from free boundaries. Eventually the bubbles collapse until the internal pressure becomes greater than the external pressure. These processes produce successive bubble pulsations that are transmitted toward the water surface or solid boundaries. Therefore, it is necessary to have adequate water depth for the explosives to take full effect during underwater blasting.

For these reasons, Equation (1) is not a good fit for the Heilong River, which has thick ice and shallow water. The river depth in the measured section ranged from 0.5 to $5.0 \mathrm{~m}$ (average $1.8 \mathrm{~m}$ ) during the winters of 2015-2017. Therefore, we sought to develop a blasting approach more appropriate for thick ice and shallow natural rivers in high latitude regions based on blasting experiments. Ice cover blasting is usually performed before the formation of ice jams and after the temperature rises above freezing, but before ice cover breakup. In this study, blasting on the Heilongjiang River was performed 15-20 days before breakup, which ensured that the ice cover was sufficiently thick and strong for the blasting operations and that the broken ice cover would not refreeze. Therefore, accurate forecasting of breakup date and ice jam occurrence is a prerequisite for the selection of a blasting date [13].

\subsection{Selection of Blasting Locations}

Historical records show that in 16 of the last 23 ice jam occurrences, the center of this phenomenon occurred in the Mohe reach along the upper Heilong River (Table 1), where the average temperature is about $-5{ }^{\circ} \mathrm{C}$, with the lowest winter temperature reaching $-59.5^{\circ} \mathrm{C}$. Thus, we concluded that the Mohe reach was an appropriate location for our ice-breaking experiments.

Table 1. Historical records of ice jam events on the Heilong River obtained from the Hydrological Bureau of Heilongjiang Province.

\begin{tabular}{|c|c|c|c|c|}
\hline Year & $\begin{array}{l}\text { Breakup Date } \\
\text { (Month-Day) }\end{array}$ & Central Location of Ice Jam & $\begin{array}{l}\text { Maximum Head } \\
\text { Increase }(\mathrm{m})\end{array}$ & $\begin{array}{l}\text { Period of Ice Jam } \\
\text { (Month-Day) }\end{array}$ \\
\hline 1950 & / & Oupu in Huma reach & 9.40 & $05-09$ to $05-11$ \\
\hline 1953 & / & Luoguhe in Mohe reach & 7.46 & $05-05$ to $05-08$ \\
\hline 1956 & / & Luoguhe in Mohe reach & 7.39 & $05-08$ to $05-10$ \\
\hline 1958 & 05-01 & Malun in Mohe reach & 10.14 & $05-05$ to $05-10$ \\
\hline 1960 & $04-26$ & Jialinda/Lianyin in Mohe reach & 13.56 & $04-27$ to $05-10$ \\
\hline 1961 & $04-27$ & Lianyin in Mohe reach & 8.03 & / \\
\hline 1964 & $04-30$ & Guchen Island in Mohe reach & 8.00 & $05-02$ to $05-14$ \\
\hline 1970 & $04-27$ & Huma in Huma reach & 5.22 & / \\
\hline 1971 & $04-23$ & Luoguhe in Mohe reach & 9.90 & $04-23$ to $05-04$ \\
\hline 1973 & $05-05$ & Guchen Island in Mohe reach & 8.20 & $05-06$ to $06-01$ \\
\hline 1977 & $05-03$ & Mohe City in Mohe reach & 6.65 & / \\
\hline 1981 & $04-23$ & Luoguhe in Mohe reach & 7.46 & $04-28$ to $04-30$ \\
\hline 1985 & $04-18$ & Jialinda/Lianyin in Mohe reach & 12.60 & $04-17$ to $05-29$ \\
\hline 1986 & $05-04$ & Jialinda/Mohe City in Mohe reach & 9.25 & $05-04$ to $05-08$ \\
\hline 1987 & $05-08$ & Oupu in Huma reach & 6.17 & / \\
\hline 1988 & $04-22$ & Kaikukang in Tahe reach & 5.11 & / \\
\hline 1991 & 05-01 & Luoguhe in Mohe reach & 8.80 & $04-28$ to $05-04$ \\
\hline 1994 & $04-29$ & Luoguhe in Mohe reach & 10.93 & $04-29$ to $05-10$ \\
\hline 1995 & $05-03$ & Luoguhe in Mohe reach & 10.10 & $05-05$ to $05-09$ \\
\hline 2000 & $04-28$ & Jinshan in Muma reach & 9.23 & $04-29$ to $05-01$ \\
\hline 2009 & $04-14$ & Hongqiling in Mohe reach & / & $04-16$ to $04-21$ \\
\hline 2010 & $04-25$ & Xingan in Mohe reach & 8.34 & $05-03$ to $05-09$ \\
\hline 2013 & $05-01$ & Mohe City in Mohe reach & / & $05-02$ to $05-07$ \\
\hline
\end{tabular}

The experimental blasting location was further refined by determining potential ice jam occurrence conditions based on simultaneous measurements of the ice cover thickness and water depth during the freeze-up period and before breakup using the new Integrated Ice-water Radar developed [19] by China Institute of Water Resources and Hydropower Research (IWHR). For example, a prototype observation of the ice cover thickness and water depth was conducted in April 2016 in the Longdao Wharf section of Beiji Town (Figure 1b), with the results shown in Figure 2. 


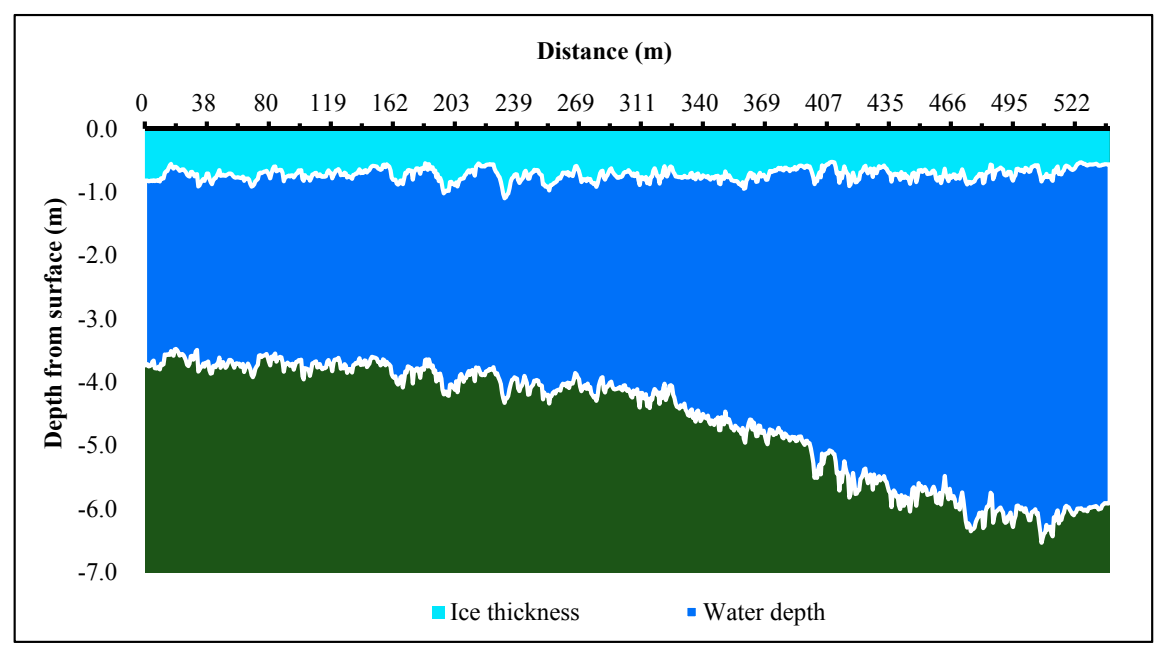

Figure 2. Ice cover thickness and water depth as measured along the Longdao Wharf section of the Mohe reach, Heilong River.

The ice cover thickness in this section ranged from 0.9 to $1.0 \mathrm{~m}$ upstream and $0.8-0.9 \mathrm{~m}$ downstream, with a rapid increase in the water depth from $3.0 \mathrm{~m}$ upstream to $6.0 \mathrm{~m}$ downstream, resulting in a $50 \%$ decrease in the water velocity. Moreover, this stretch is located along a river bend, resulting in increased resistance to ice flow [20,21]. These factors can cause ice blocks to accumulate in the downstream portion of the reach because of increased flow resistance and decreased velocity [22-24]. As a result, there was potential for an ice jam to occur downstream of this section, so ice blasting was conducted here to prevent ice jam occurrence before breakup in 2016.

\subsection{Challenges to the Study of Blasting Craters}

Several challenges exist for ice blasting and observation on the Heilongiiang River. First, it is difficult to measure ice blasting data due to factors including thick ice cover and snow on the ice, a lack of topographic information for the entire river channel, harsh weather, and inconvenient transportation systems. Second, some blasting craters have a clear demarcation between the fragmented ice of the central crater and the surrounding intact ice. Other craters have a central zone with heavily fragmented ice, surrounded by ice that has been flexed and cracked, and there is no clear demarcation in place. Moreover, the edge of the blasting crater and surrounding cracks are usually covered by snow and broken ice, making it difficult to accurately determine the blasting boundary and the length of the cracks. Third, it is difficult and dangerous for the researchers to get too close to the blasting crater after blasting, such that measurements of the blasting crater radius are usually performed outside the crater, leading to potential errors (especially between different surveyors).

In addition, due to constraints on site conditions, the range of some experimental data (such as ice cover thickness and water depth) is limited. We collected a total of 214 sets of effective data based on hundreds of field observations from 2015 to 2017. In order to ensure that the diameters of all blasting craters could be independently measured, a sufficient distance was maintained between each location. The explosives were placed under the ice cover based on the principal proposed by the USACE [6], i.e., that the optimal location should be $0-0.6 t$ below the ice cover; this meant that the impact of the explosives' location below the ice cover was neglected during this study.

\subsection{Regression Analysis for Ice-Blasting Variables}

A basic requirement in ice blasting is to predict the crater size as the dependent variable by establishing the relationship between the blasting crater radius $\left(R_{c}\right)$ and other relevant variables based on large amounts of measurement data and field observations. The relevant variables, representing the input data for the prediction, include the explosive weight $(W)$, water depth below the ice $\left(h_{c}\right)$, 
explosive depth under the ice cover $\left(d_{c}\right)$, and ice cover thickness $(t)$. The relationship between the blasting crater radius and other relevant variables is built by regression analysis. However, as the number of data sets available for regression analysis is rather small, it is necessary to somehow reduce the number of variables. One approach is to express one variable in terms of another. Based on Mellor's conclusions for underwater blasting, a useful parameter is cube root scaling [11]. All linear dimensions of these variables are divided by the cube root of explosive weight. In this case of constant explosive density, the lengths are effectively dimensionless since the dimension of the cube root of explosive weight represents that of the crater radius. By scaling the crater radius, the ice cover thickness, and the water depth, two independent variables are left, as defined below:

The scaled crater radius $Y$ is:

$$
Y=R_{c} / W^{\frac{1}{3}}
$$

where $R_{c}$ is the scaled blasting crater radius $(\mathrm{m})$ and $W$ is the explosives weight $(\mathrm{kg})$. The scaled ice cover thickness $X_{1}$ is:

$$
X_{1}=t / W^{\frac{1}{3}}
$$

where $t$ is the ice cover thickness. The scaled water depth below the ice cover $X_{2}$ is:

$$
X_{2}=h_{c} / W^{\frac{1}{3}}
$$

where $h_{c}$ is the water depth $(\mathrm{m})$. The chosen regression equation is a polynomial equation with cross-products and terms up to the third power:

$$
Y=b_{0}+b_{1} X_{1}+b_{2} X_{2}+b_{3} X_{1}^{2}+b_{4} X_{1} X_{2}+b_{5} X_{2}^{2}+b_{6} X_{1}^{3}+b_{7} X_{1}^{2} X_{2}+b_{8} X_{1} X_{2}^{2}+b_{9} X_{2}^{3}
$$

\section{Results}

\subsection{Behavior and Characteristics of Blasting Craters}

The blasting process follows a predictable sequence: blasting starts, then the shock wave rises, reaches its peak (Figure 3), dissipates, and disappears. The entire process usually lasts about $20 \mathrm{~s}$ and results in a crater surrounded by a mixture of broken ice blocks and snow. Three typical types of blasting craters occur in Heilong River: mountain-shaped, standard, and fully broken (Figure $4 a-c)$.

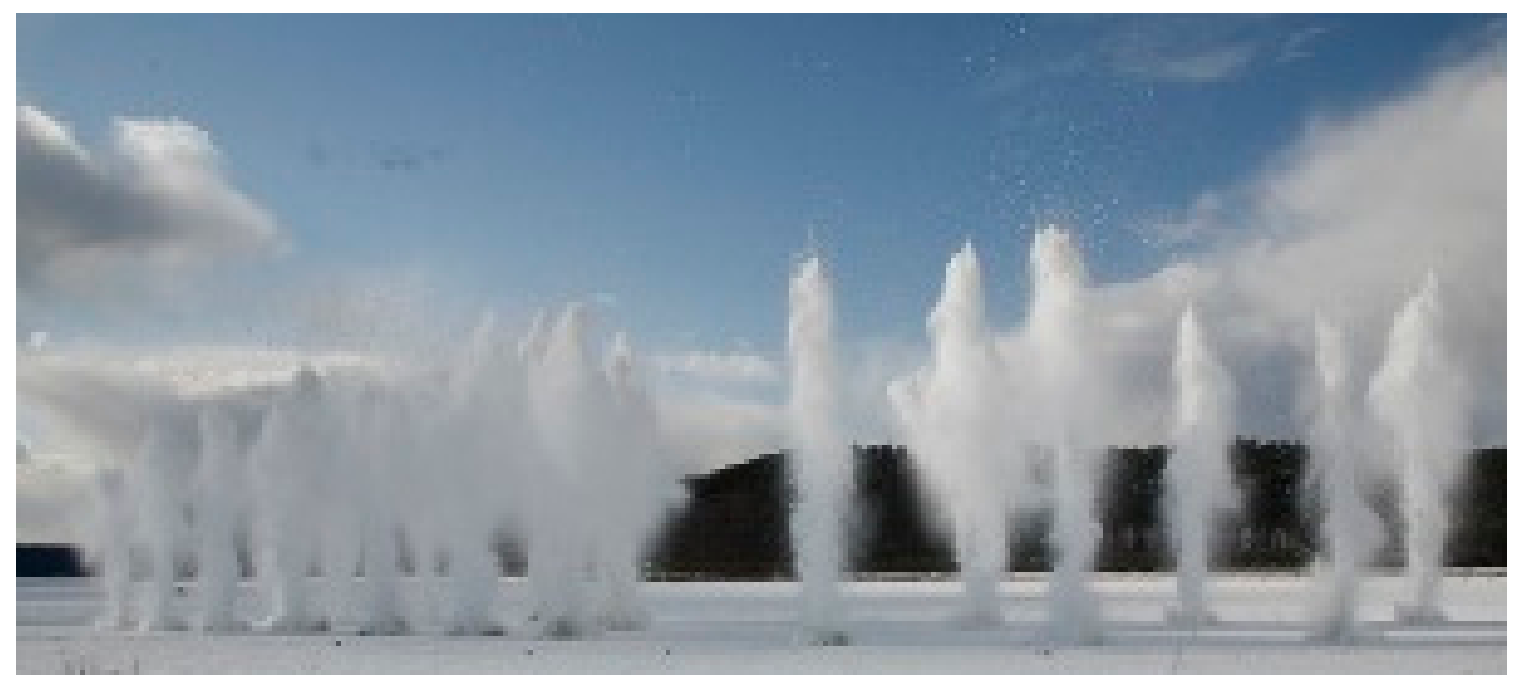

Figure 3. Example of ice cover blasting in the Mohe reach, Heilong River. 

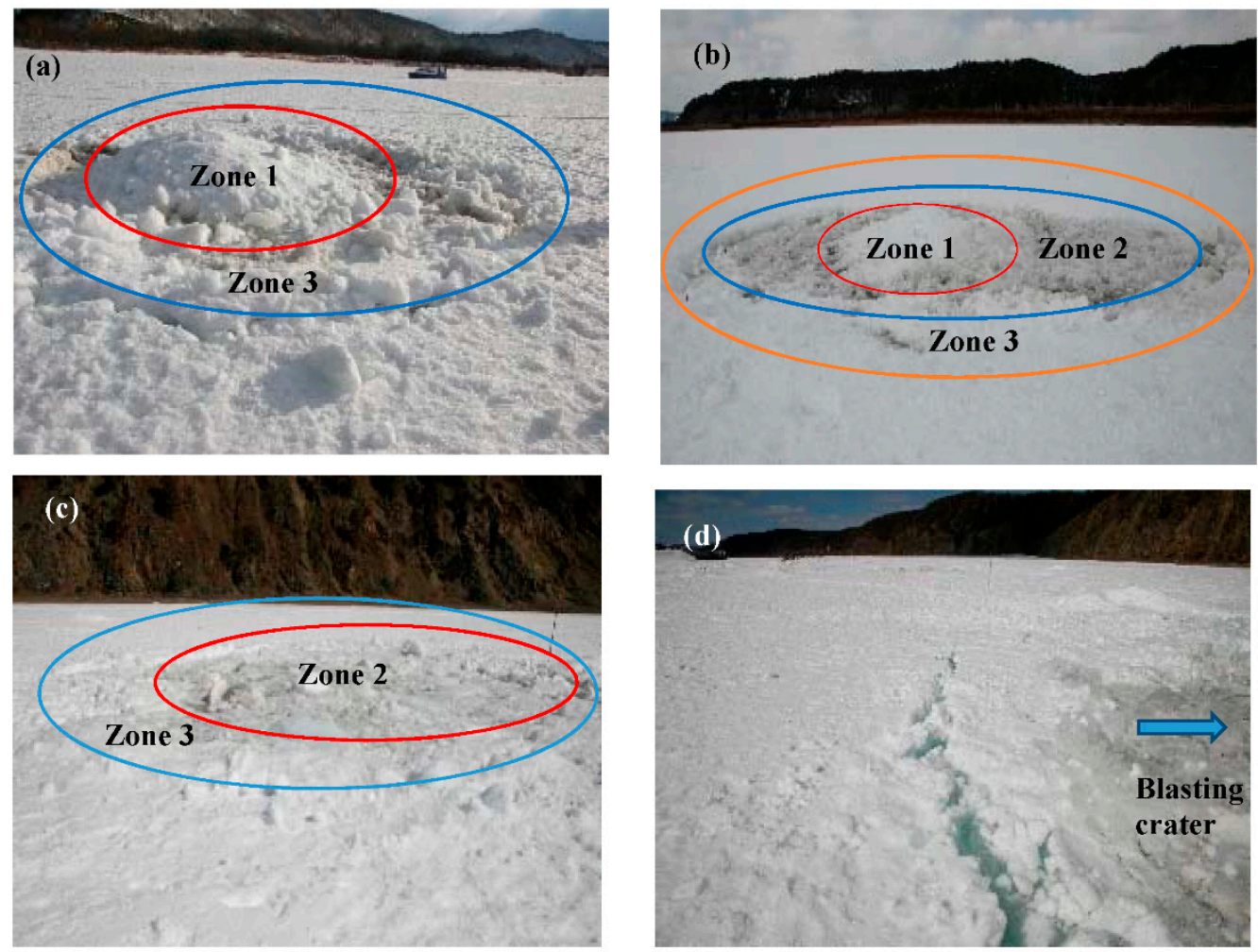

Figure 4. Typical blasting crater types and post-blasting features: (a) mountain-shaped; (b) standard; (c) fully broken; (d) post-blasting ice cracks.

Three distinct zones of physical features can form in blast craters, though these are distributed differently among the three types of craters. Zone 1 consists of broken ice and snow piled into a mountain-like structure. Zone 2 is the fully broken blasting zone, consisting primarily of water and floating broken ice on the water surface. Zone 3 is the cracked zone, containing cracks under the snow or broken ice. Figure $4 \mathrm{~d}$ shows a typical crack through the ice cover outside of the blasting crater with a center width of about $10 \mathrm{~cm}$ and a depth of about $35 \mathrm{~cm}$.

\subsection{Relationship between Blasting Crater Radius and Ice Cover Thickness}

The measured ice cover thickness ranged from 0.51 to $1.55 \mathrm{~m}$ and the measured blasting crater diameter ranged from 4.6 to $21.6 \mathrm{~m}$ (Figure 5). As the amount of the explosives increased, the blasting crater diameter also increased significantly. For a given amount of the explosives, the blasting crater diameter increased slightly with increasing ice cover thickness. Other studies have shown that, under the same explosive weight, once the ice cover thickness exceeds a certain value the blasting crater diameter starts to decrease with increasing ice cover thickness [6].

The trinomial and binominal forms of the regression equation given in Equation (5) are shown in Equations (6) and (7), which express the relationship between the scaled blasting crater radius and the scaled ice cover thickness:

$$
\begin{gathered}
Y=3.08-2.69 X_{1}+5.57 X_{1}^{2}-3.26 X_{1}^{3} \text { and } \\
Y=2.67+0.06 X_{1}+0.056 X_{1}^{2}
\end{gathered}
$$




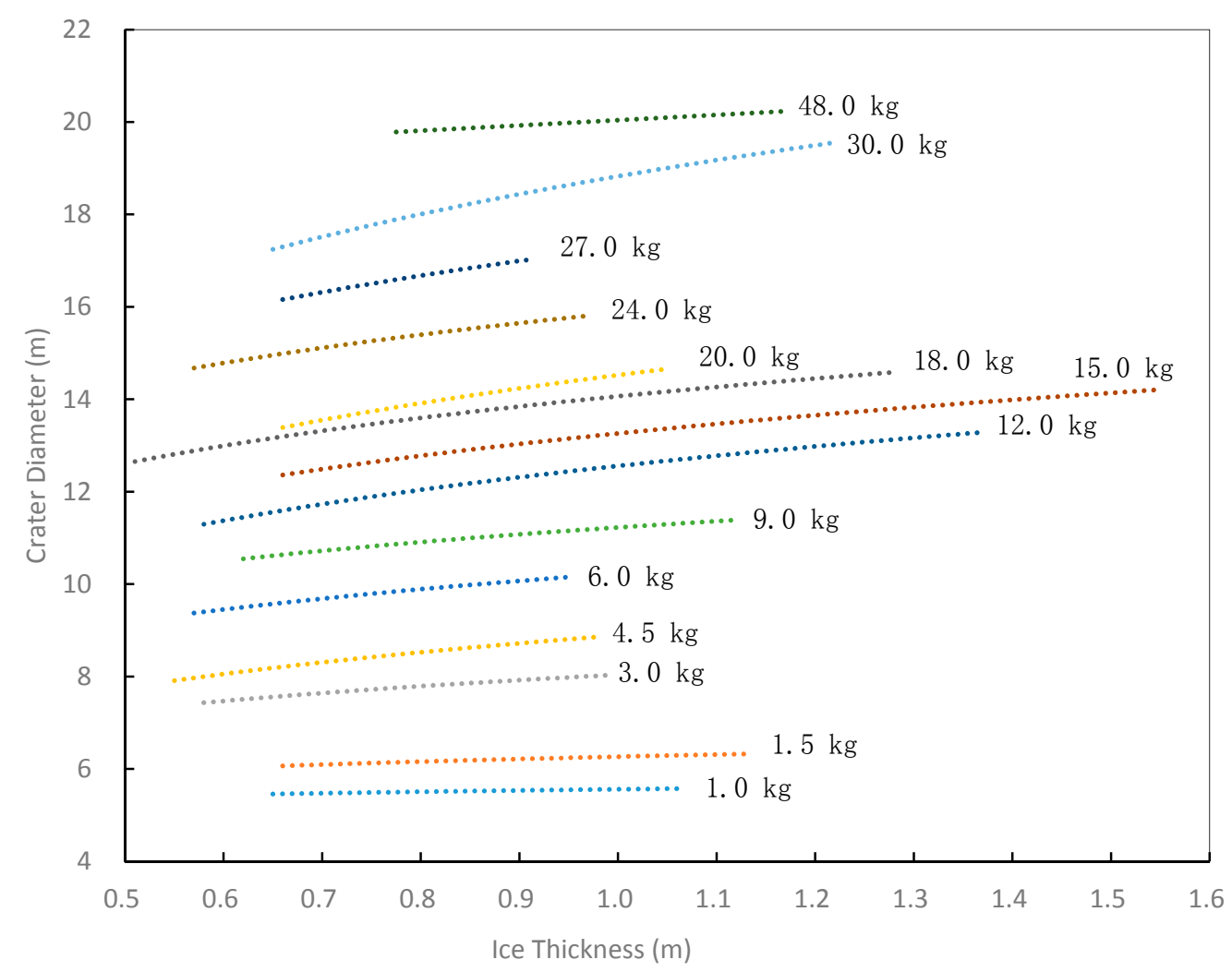

Figure 5. Relationship between measured blasting crater diameter and ice cover thickness.

\subsection{Relationship between Water Depth, Blasting Crater Radius, and Ice Cover Thickness}

The Heilong River has many branches and shallow sand bars. Furthermore, blasting locations are limited to the south side of the river, within Chinese territory, since the river forms the border between China and Russia. The above factors lead to relatively shallow water in the blasting area, where the maximum measured water depth is less than $5.0 \mathrm{~m}$.

When a concentrated blast is detonated well below the water's surface, it propagates a spherical shock wave at high velocity and creates a gas bubble, as shown in Figure 6 [6]. This wave's pressure decays with distance, largely because of spherical spreading. The radial distance from explosives of different weight can be scaled with respect to the crater size. Therefore, it is important to have sufficient underwater distance for the explosives to take full effect during blasting.

In our tests, large amounts of explosives could not take full effect in areas with shallow water (Figure 7). When the explosive weight was $1.0-9.0 \mathrm{~kg}$, at shallow water depths the crater diameter increased slightly, but from around $2.0 \mathrm{~m}$ to $5.0 \mathrm{~m}$ the blasting crater diameter remained nearly the same, demonstrating that explosives could take full effect at water depths over $2 \mathrm{~m}$ for these explosive weights. However, when the explosive weight was $12.0-15.0 \mathrm{~kg}$, as the water depth increased the blasting crater diameter increased more rapidly, and did not level off as did lower explosive weights. When the explosive weight was $20.0-30.0 \mathrm{~kg}$, due to the limitations of the field conditions, the water depth was limited to $0.5-2.5 \mathrm{~m}$. The same trend was seen for $20.0 \mathrm{~kg}$ explosive weight as for $12.0-15.0 \mathrm{~kg}$ (up to the depth limit) but for weights above this, the blasting crater diameter increased rapidly with water depth in a distinctly different trend. This analysis shows that, at water depths less than $2.5 \mathrm{~m}$, there is insufficient distance for larger explosive weights to take full effect. 


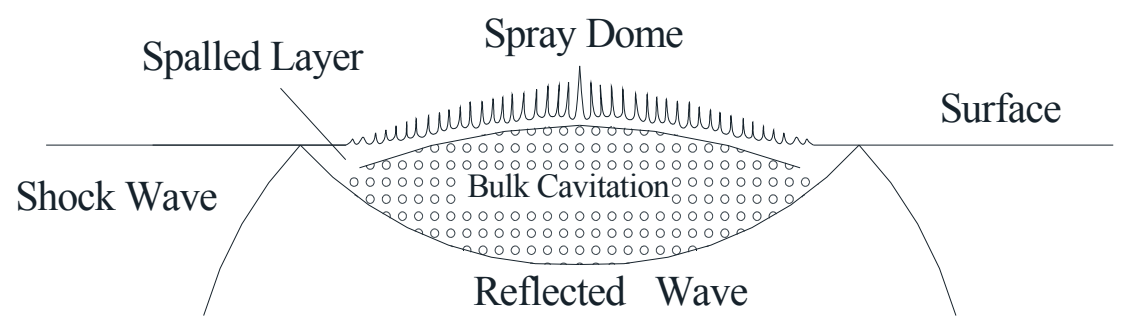

Gas

Bubble

Figure 6. Surface spalling by an underwater explosion.

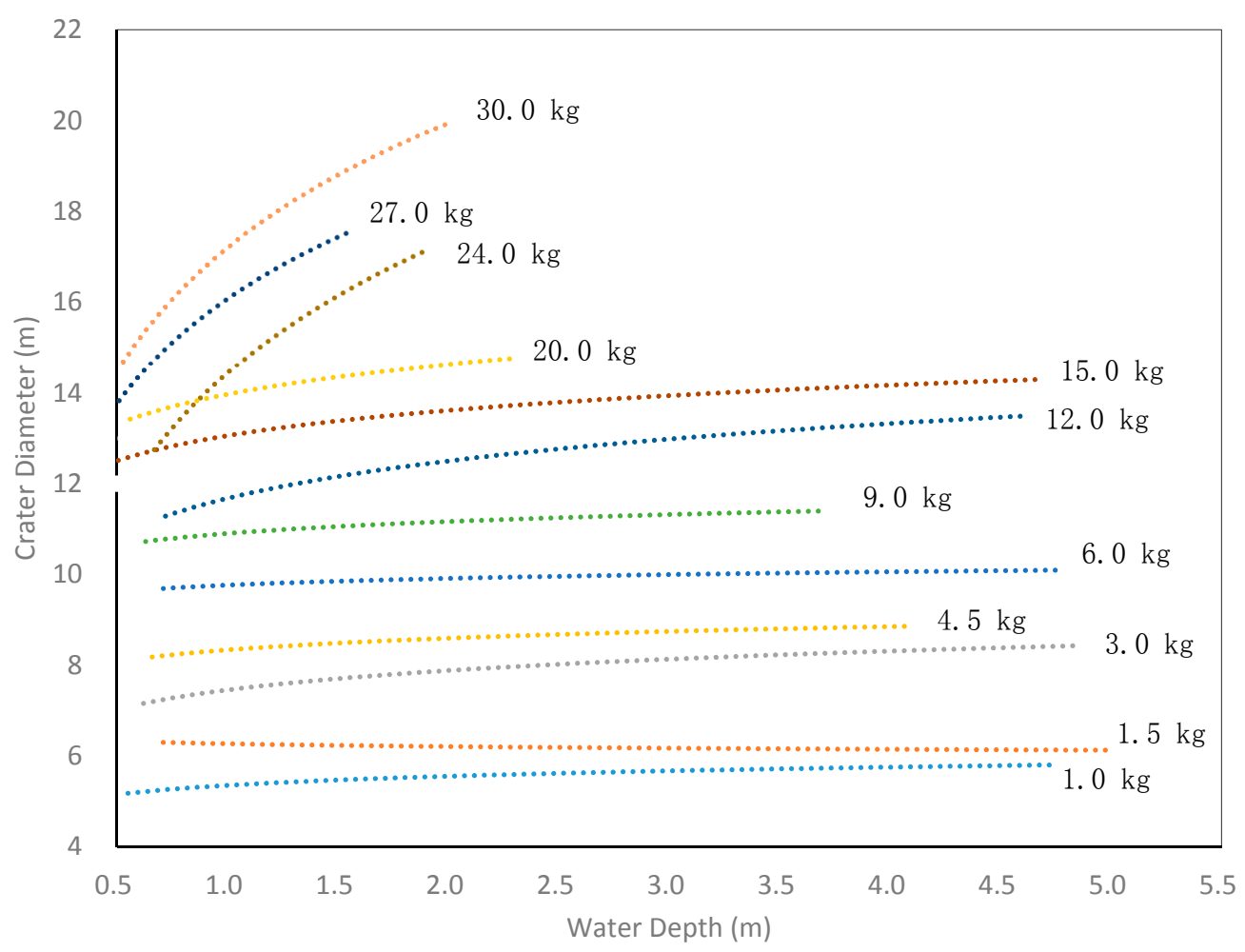

Figure 7. Relationship between measured blasting crater diameter and water depth below ice.

The relationships between the scaled blasting crater radius, scaled ice cover thickness, and scaled water depth were developed using regression analysis as shown in trinomial (cross trinomial and pure trinomial) and binomial (cross binomial and pure binomial) forms:

$$
\begin{gathered}
Y=3.30-7.77 X_{1}+2.09 X_{2}+15.41 X_{1}{ }^{2}-2.63 X_{1} X_{2}-0.67 X_{2}{ }^{2}-8.74 X_{1}{ }^{3} \\
+1.73 X_{1}^{2} X_{2}+0.01 X_{1} X_{2}^{2}+0.10 X_{2}{ }^{3} \\
Y=3.20-6.12 X_{1}+1.51 X_{2}+10.09 X_{1}{ }^{2}-0.81 X_{2}{ }^{2}-5.13 X_{1}{ }^{3}+0.12 X_{2}^{3} \\
Y=2.75-1.01 X_{1}+0.41 X_{2}+0.98 X_{1}{ }^{2}-0.31 X_{1} X_{2}-0.03 X_{2}{ }^{2} \\
Y=2.73-0.75 X_{1}+0.32 X_{2}+0.42 X_{1}{ }^{2}-0.06 X_{2}{ }^{2}
\end{gathered}
$$




\subsection{Proposed Formula and Analysis of Experiment Results}

The effectiveness of our proposed formula can be assessed using the root mean square error and correlation coefficients:

$$
\begin{gathered}
R M S E=\sqrt{\frac{\sum_{i=1}^{N}(X(i)-Y(i))^{2}}{N}} \\
r=\frac{N\left(\sum X Y\right)\left(\sum X\right)\left(\sum Y\right)}{\sqrt{\left(N \sum X^{2}\left(\sum X\right)^{2}\right)\left(N \sum Y^{2}\left(\sum Y\right)^{2}\right.}}
\end{gathered}
$$

where RMSE is the root mean square error, $r$ is the correlation coefficient, $X$ is the measured data, $Y$ is the predicted data, and $N$ is the total number of sample sequences. The smaller the RMSE, the smaller the difference between the predicted value and the measured value is. However, the closer the $r$ value is to 1 , the closer these values are.

The RMSE and $r$ values were compared using the results predicted by Equations (6)-(11) and the measured values (Table 2). Ignoring the impact of water depth and only considering the relationship between blasting crater radius and ice cover thickness, the RMSEs of the trinomial Equation (6) and binomial Equation (7) were higher than those of Equations (8)-(11), which considered the impact of water depth, while the correlation coefficients of Equations (6) and (7) were lower than those of Equations (8)-(11). These results demonstrate that the impact of water depth cannot be ignored when assessing ice blasting in the Heilong River. In addition, the results of the trinomial equations were better than those of the binomial equations, and the cross trinomial and cross binomial equations were better than the corresponding pure trinomial and pure binomial equations.

Table 2. Evaluation of predicted and experimental results using different regression methods.

\begin{tabular}{lccc}
\hline \multicolumn{1}{c}{ Conditions } & Type of Regression & \multicolumn{2}{c}{ Evaluation Method } \\
\cline { 3 - 4 } & Equation & $\begin{array}{c}\text { Root Mean Square } \\
\text { Error (RMSE) }\end{array}$ & $\begin{array}{c}\text { Correlation } \\
\text { Coefficient }(r)\end{array}$ \\
\hline Relation between scaled blasting crater & Pure binomial Equation (6) & 0.8686 & 0.9087 \\
radius and scaled ice cover thickness & Pure binomial Equation (7) & 0.8745 & 0.9073 \\
\hline Relation between scaled blasting crater & Cross trinomial Equation (8) & 0.7577 & 0.9371 \\
radius, ice scaled thickness, and scaled & Pure trinomial Equation (9) & 0.7621 & 0.9311 \\
water depth & Cross binomial Equation (10) & 0.8294 & 0.9184 \\
& Pure binomial Equation (11) & 0.8308 & 0.9180 \\
\hline
\end{tabular}

We further considered the relative errors from Equations (8)-(11) (Table 3). The prediction errors from the two trinomial equations were very close (no more than 7.5\%), as were those from the two binomial equations (no more than 8.5\%). For simplicity, we used the pure trinomial Equation (9) for calculations of blasting crater radius. Inserting the explosive weight, ice cover thickness, water depth, and blasting crater radius into Equation (9), the following equation was obtained:

$$
R_{c}=3.20 W^{1 / 3}-6.12 t+1.51 h_{c}+10.09 t^{2} / W^{\frac{1}{3}}-0.81 h_{c}^{2} / W^{\frac{1}{3}}-5.13 t^{3} /\left(W^{\frac{1}{3}}\right)^{2}+0.12 h_{c}^{2} /\left(W^{\frac{1}{3}}\right)^{2}
$$

Table 3. Relative errors between predicted and measured blasting crater radius.

\begin{tabular}{ccccc}
\hline \multirow{2}{*}{ Relative Error } & \multicolumn{2}{c}{ Trinomial Equations } & \multicolumn{2}{c}{ Binomial Equations } \\
\cline { 2 - 5 } & $\begin{array}{c}\text { Cross Trinomial } \\
\text { Equation (8) }\end{array}$ & $\begin{array}{c}\text { Pure Trinomial } \\
\text { Equation (9) }\end{array}$ & $\begin{array}{c}\text { Cross Binomial } \\
\text { Equation (10) }\end{array}$ & $\begin{array}{c}\text { Pure Binomial } \\
\text { Equation (11) }\end{array}$ \\
\hline Average relative error & 7.4 & 7.5 & 8.4 & 8.5 \\
Max relative error & 24.6 & 24.7 & 25.9 & 26.2 \\
Min relative error & 0.0 & 0.1 & 0.1 & 0.0 \\
\hline
\end{tabular}


Comparing the predicted and measured blasting crater radii (Figure 8), it is clear that both trends are similar. The prediction results for Equations (8)-(11) were very close; the difference in the mean relative error based on the binomial and trinomial equations was within $1 \%$. To further simply future calculations, the pure binomial Equation (11) can thus be used by inserting the explosive weight, ice cover thickness, water depth, and blasting crater radius terms into Equation (11) to obtain:

$$
R_{c}=2.73 W^{\frac{1}{3}}-0.75 t+0.32 h_{c}+0.42 t^{2} / W^{\frac{1}{3}}-0.06 h_{c}^{2} / W^{\frac{1}{3}}
$$

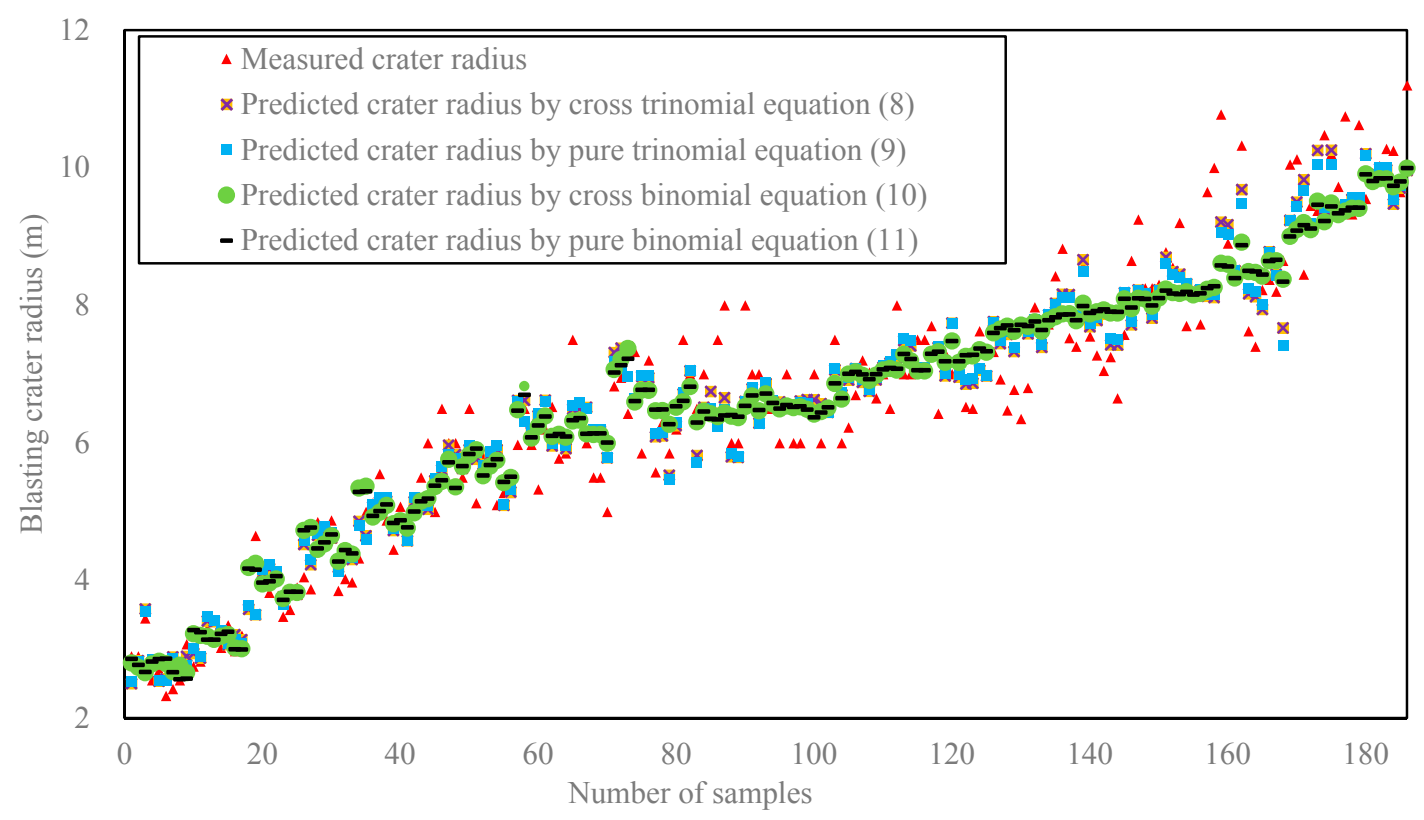

Figure 8. Scatter diagram of measured and predicted blasting crater radii.

\section{Conclusions}

The Heilong River, which serves as the border between China and Russia, has wide and shallow channels along with thick ice cover in winter. The use of ice blasting with explosives to prevent ice jam formations before spring breakup requires consideration of these special characteristics. Although the type of explosive used is unimportant, ice blasting experiments and field observations show that when the optimal principle recommended by the USACE is adopted for the depth of explosives below the ice cover, the blasting crater radius is affected not only by the explosive weight and ice cover thickness, but also by the water depth. We developed equations to express the relationship between the blasting crater radius and the ice cover thickness, explosive weight, and water depth below ice cover using the regression method. Based on analyses of the correlation coefficients, root mean square errors, and relative errors by these equations, we proposed Equation (15) to describe the relationship between these variables due to its small error range, strong correlations, and simple format. The average relative error between the predicted and measured values was no more than $8.5 \%$. The proposed equation is applicable to both natural rivers with thin ice cover and shallow rivers with thick ice cover.

The methods proposed in this study were used for ice blasting in the Mohe reach of the upper Heilong River in spring 2016 before breakup and successfully avoided the formation of ice jams. The precipitation during freeze-up and before breakup was $51 \%$ and $74 \%$ higher than the annual average, respectively, and in 2016 the amount of precipitation in April was 77\% higher than the multi-year average rainfall. Based on ice jam prediction and field measurements, these favorable conditions created the potential for an ice jam to occur at the test locations, but this did not happen during breakup due to the proactive ice blasting performed in our study. 
Other regions facing similar conditions could benefit from the application of these methods. For example, rivers that face the harsh conditions of a Siberian winter, and China's Songhua and Nen Rivers (the two longest tributaries in the Heilong River Basin), face similar ice conditions to the Heilong River, in which ice jams often occur during breakup. The equations developed here have been suggested for application to Songhua and Nen Rivers by the Flood Control and Drought Relief Office of Heilongjiang Province, which will help to supplement the current research data.

Finally, our results and conclusions were limited by the local river conditions and the effect of water depth on explosive performance; future studies should explore the impacts of these variables and test the methods suggested here under diverse conditions.

Author Contributions: Each author has made substantial contributions to the work of the manuscript. All authors have approved the submitted version and agreed to be personally accountable for the author's own contributions. X.G. conceived and designed the experiments; T.W., H.F., and J.L. performed the experiments; Y.G., Y.X., and X.G. analyzed the data; X.P. and Y.W. contributed reagents/materials/analysis tools; T.W. wrote the paper.

Funding: This research was funded by the National Key Research \& Development Plan of China (grant numbers 2017YFC0405103 and 2017YFC0405704), IWHR Research \& Development Support Program (grant numbers HY0145B642017, SKL2017CGS04, and HY0145B912017), the Special Scientific Research Fund of Public Welfare Profession of China (grant numbers 201501025 and 201301032).

Acknowledgments: The authors also appreciate the support from the Water Resources Department of Heilongiiang Province, the Support Centre of Flood Control and Drought Relief of Heilongjiang Province, and the Mohe Hydrologic Administration during the ice blasting experiments.

Conflicts of Interest: The authors declare no conflict of interest. The founding sponsors had no role in the design of the study; in the collection, analyses, or interpretation of data; in the writing of the manuscript, and in the decision to publish the results.

\section{References}

1. Beltaos, S. River Ice Jams; Water Resources Publications: Littleton, CO, USA, 1995.

2. Beltaos, S. River Ice Breakup; Water Resource Publication: Littleton, CO, USA, 2008.

3. Shen, H.T. Research on River Ice Processes, Progress and Missing Links. J. Cold Reg. Eng. 2003, 17, 135-142. [CrossRef]

4. Zhang, F.; Mosaffa, M.; Chu, T.; Lindenschmidt, K.-E. Using remote sensing data to parameterize ice jam modeling for a Northern Inland Delta. Water 2017, 9, 306. [CrossRef]

5. Mellor, M. Derivation of guidelines for blasting floating ice. Cold Reg. Sci. Technol. 1987, 13, 193-206. [CrossRef]

6. Mellor, M. Breaking Ice with Explosives; Cold Regions Research \& Engineering Laboratory, US Army Corps of Engineers: Hanover, NH, USA, 1982; p. 3.

7. Ding, L.Q.; He, B.S.; Yan, X.G. New technology of breaking ice to ice prevention. China Flood Drought Manag. 2010, 2, 19-24. (In Chinese)

8. Liang, X.Q.; He, B.S.; Xie, W.H. Experiment study on the blasting upon thick ice. Eng. Blast. 2012, 18, 83-85. (In Chinese)

9. Tong, Z.; Yang, X.S.; Xue, P.X. Ice-Broken Explosion Mechanism of Yellow River/New Blasting Technology in China III; Metallurgical Industry Press: Beijing, China, 2012; pp. 57-66. (In Chinese)

10. Duan, Y.S.; Wang, X.H.; Liu, S.B. Application of blasting technique to against ice jam. J. Glaciol. Geocryol. 2003, 220-226. Available online: http:/ / caod.oriprobe.com/articles/32266117/Application_of_Blasting_ Technique_to_Against_Ice_Jam.htm (accessed on 22 May 2018). (In Chinese)

11. Yin, H.T.; Yang, X.H.; Jiang, M.; Jin, J.L. Experimental research on ice breaking by extended blasting cartridge under ice. Eng. Blast. 2010, 16, 12-15. (In Chinese)

12. Wang, T.; Yang, K.L.; Guo, Y.X. Application of artificial neural networks to forecasting ice conditions of the Yellow River in the Inner Mongolia Reach. J. Hydrol. Eng. 2008, 13, 811-816.

13. Wang, T.; Liu, Z.P.; Guo, X.L.; Fu, H.; Liu, W. Prediction of breakup ice jam with artificial neural networks. J. Hydraul. Eng. 2017, 48, 1355-1362. (In Chinese)

14. Xia, L.F. Research and practice of underwater ice jam breaking by manual-operated blasting. Blasting 2014, 31, 126-130. (In Chinese) 
15. Shi, R.; Xu, G.G.; Liu, D.R.; Qin, J. Underwater test and analysis for explosion energy of explosives. Chin. J. Explos. Propellants 2008, 31, 1-5. (In Chinese)

16. Liang, X.Q.; Xiong, F.; Lu, X.L. Experimental research on underwater shock wave characteristic of ice blasting at Yellow River. Blasting 2014, 4, 1-4. (In Chinese)

17. Dai, C.L.; Yu, C.G.; Liao, H.C.; Zhang, B.S. Survey and Forecast of River Ice; China Water \& Power Press: Beijing, China, 2010. (In Chinese)

18. Yu, T.C.; Wang, X.F.; Wang, J.L. Underwater shockwave performance of explosives. Energ. Mater. 2003, 11, 182-186. (In Chinese)

19. Liu, Z.P.; Fu, H.; Guo, X.L.; Wang, T.; Cui, H. Double frequency radar system for ice thickness and water depth measurement. J. Hydraul. Eng. 2017, 48, 1341-1347. (In Chinese)

20. Bonanno, R.; Loglisci, N.; Cavalletto, S.; Cassardo, C. Analysis of different freezing/thawing parameterizations using the UTOPIA Model. Water 2010, 2, 468-483. [CrossRef]

21. Wang, J.; Sui, J.Y.; Zhang, H.Y.; Chen, P.; Hirshfield, F. Mechanisms of ice accumulation in a river bend-An experimental study. Int. J. Sediment Res. 2012, 27, 521-537. [CrossRef]

22. Guo, X.L.; Yang, K.L.; Fu, H.; Xia, Q.; Wang, T.; Yang, S. Ice processes modeling during reverse water transfer of open canals: A case study. J. Hydro-Environ. Res. 2017, 17, 56-67. [CrossRef]

23. Shen, H.T.; Gao, L.; Kolerski, T.; Liu, L. Dynamics of ice jam formation and release. J. Coast. Res. 2008, 24, 25-32. [CrossRef]

24. Kolerski, T.; Shen, H.T. Possible effects of the 1984 St. Clair River ice jam on bed changes. Can. J. Civ. Eng. 2015, 42, 696-703. [CrossRef]

(c) 2018 by the authors. Licensee MDPI, Basel, Switzerland. This article is an open access article distributed under the terms and conditions of the Creative Commons Attribution (CC BY) license (http://creativecommons.org/licenses/by/4.0/). 